\title{
Indian summer monsoon variability forecasts in the North American multimodel ensemble
}

\author{
Bohar Singh ${ }^{1} \cdot$ Ben Cash ${ }^{2}$ James L. Kinter III'
}

Received: 31 December 2016 / Accepted: 19 February 2018 / Published online: 12 April 2018

(C) The Author(s) 2018

\begin{abstract}
The representation of the seasonal mean and interannual variability of the Indian summer monsoon rainfall (ISMR) in nine global ocean-atmosphere coupled models that participated in the North American Multimodal Ensemble (NMME) phase 1 (NMME:1), and in nine global ocean-atmosphere coupled models participating in the NMME phase 2 (NMME:2) from 1982-2009, is evaluated over the Indo-Pacific domain with May initial conditions. The multi-model ensemble (MME) represents the Indian monsoon rainfall with modest skill and systematic biases. There is no significant improvement in the seasonal forecast skill or interannual variability of ISMR in NMME:2 as compared to NMME:1. The NMME skillfully predicts seasonal mean sea surface temperature (SST) and some of the teleconnections with seasonal mean rainfall. However, the SST-rainfall teleconnections are stronger in the NMME than observed. The NMME is not able to capture the extremes of seasonal mean rainfall and the simulated Indian Ocean-monsoon teleconnections are opposite to what are observed.
\end{abstract}

Keywords Indian Monsoon $\cdot$ Interannual variability $\cdot$ Teleconnections

\section{Introduction}

The variations of the seasonal rainfall associated with the south Asian monsoon are enormously important for millions of lives on the Indian subcontinent and beyond. The spatial and temporal variations of rainfall have a significant impact on the agrarian economies of India, Bangladesh and Pakistan. While interannual variations in Indian summer monsoon rainfall (ISMR) are only $\approx 10 \%$ of the long term mean, the high and low extremes of the seasonal mean

This paper is a contribution to the special collection on the North American Multi-Model Ensemble (NMME) seasonal prediction experiment. The special collection focuses on documenting the use of the NMME system database for research ranging from predictability studies, to multi-model prediction evaluation and diagnostics, to emerging applications of climate predictability for subseasonal to seasonal predictions. This special issue is coordinated by Annarita Mariotti (NOAA), Heather Archambault (NOAA), Jin Huang (NOAA), Ben Kirtman (University of Miami) and Gabriele Villarini (University of Iowa).

Bohar Singh

bsingh5@gmu.edu

George Mason University, Fairfax, VA 22031, USA

2 Center for Ocean-Land-Atmosphere Studies, George Mason University, Fairfax, VA 22031, USA
ISMR result in floods and droughts (Shukla and Moolay 1987). Food production in the Indian region is strongly correlated with ISMR (Gadgil et al. 1999), and these floods and droughts can cause devastating human and economic losses. The south Asian monsoon is recognized as a prominent feature of the global circulation (Lau and K.-M. Kim 2006). Continental-scale land-sea contrast has been suggested as primary cause for the monsoon (Webster et al. 1998), while other studies suggest it is driven by the meridional movement of the Intra-Tropical Convergence Zone (ITCZ) (Gadgil et al. 2003). Besides these two basic components the ISMR is also influenced by the topography of Great Himalaya, which introduces an elevated heating source and helps to set the meridional tropospheric temperature gradient. The local reversal of the meridional tropospheric temperature gradient during the summer is thought to be important for the onset of the ISMR. This gradient is maintained in part by the heat fluxes and diabatic heating due to precipitation (Yanai et al. 1992; Wu and Zhang 1998). The topography of Himalaya isolates the Indian monsoon thermal maximum from the dry and cold air in the interior of Asian continent (Chakraborty et al. 2002; Boos and Kuang 2010), and numerical modeling studies have found that by removing the topography the northern extent of the precipitation is greatly reduced (e.g., Hahn and Manabe 
1975; Prell and Kutzbach 1992). Another key feature of the monsoon circulation is the climatological low over northwestern India and Pakistan, which is the deepest low in the global tropics during boreal summer (Joshi and Desai 1985; Sikka 1997). It develops in April-May concurrently with the south-westerly wind regime (Ramage 1996). The high winds associated with the monsoon trough not only bring moisture over the land but also natural dust and aerosols. Aerosols can influence the monsoon through direct (interaction with solar radiation) and indirect (interaction with cloud microphysics) effects (Bollasina et al. 2011; Lau and K.-M. Kim 2006). Slowly varying boundary conditions such as SST, snow cover and soil moisture are also key components of the Indian monsoon, particularly in terms of its potential predictability (Charney and Shukla 1981). The teleconnection between southern oscillation and ISMR is among the oldest observed teleconnections (Walker 1925). Observational analysis shows that indian summer monsoon rainfall found below average during El Niño events, while La Niña events lead to above normal rainfall (e.g. Sikka 1980; Pant and Parthasarathy 1981; Rasmusson and Carpenter 1983; Gadgil et al. 2003, 2004). Niño 3.4 index (standardized area average SST average over the region $170^{\circ} \mathrm{E}-120^{\circ} \mathrm{W}, 5^{\circ} \mathrm{S}-5^{\circ} \mathrm{N}$ ) is negatively correlated with ISMR. The observed negative correlation between the ISMR and Niño 3.4 index can be explained to some extent by the modulation of the Walker circulation (Shukla and Paolino 1983; Palmer et al. 1992). Thus, the Indian monsoon includes a complex orographically influenced structure, interaction between convection and large-scale atmospheric circulation, wave propagation in both the zonal and meridional directions, air-sea interaction, and cloud-aerosol interaction. Due to the presence of all the above components and their nonlinear interactions, Indian monsoon rainfall is an extremely challenging phenomenon to simulate (Gadgil et al. 2005).

Uncertainties and model errors in climate prediction can be classified into two groups: (1) uncertainties and errors in model initialization and (2) uncertainties and errors in model parameterizations and model physics (Buizza et al. 2005; Schwierz et al. 2006). The multi-model ensemble (MME) is recognized as one approach to address the above-mentioned uncertainties and errors (Palmer et al. 2004, 2005; Hagedorn et al. 2004). MMEs typically have higher skill for predicting weather and climate as compared to single models, and also provide estimates of model uncertainty. The simulation and prediction of ISMR at both inter-annual and intra-seasonal time scales has been evaluated in several such MMEs (Gadgil and Sajani 1998; Kang et al. 2002; Rajeevan and Nanjundiah 2009; Sperber et al. 2013; Wang et al. 2004, 2004). All MMEs examined previously have been shown to simulate large-scale feature of Indian rainfall with modest skill. Some studies (Wang et al. 2003; Sharmila et al. 2013) have highlighted the importance of air-sea interactions and suggest that coupled ocean-atmospheric models are crucial for monsoon seasonal predictions. Preethi et al. (2010) and Rajeevan et al. (2012) evaluated the seasonal forecast skills of Development of European multi-model ensemble system for seasonal to interannual predictions (DEMETER) (Palmer et al. 2004) and ENSEMBLE (Hewitt and Griggs 2004) projects respectively and found that these multi-model ensembles predict ISMR with positive (modest) skill. The realized skill is still below the limit of potential predictability (Saha et al. 2016).

In this study we investigate the ability of the North-American Multi Model Ensemble (NMME) models to reproduce and predict the seasonal mean and interannual variability of the Indian summer monsoon rainfall. The NMME is a collaborative effort between several modeling centers for seasonal forecasts. The NMME simulations provides us with the opportunitiy to compare the simulations from multiple seasonal models for the same phenomenon. The analysis of the multi-model simulations for identical scenarios will aid us in identifying and understanding the similarities and differences of the various model simulations. The study of Kirtman et al. (2014) have shown that modeling system improvements and data assimilation system improvements led to improved NMME-2 forecast quality. The second objective of this study is to compare the seasonal forecast skill of NMME phase 1 with the currently operational NMME phase 2 to understand whether the improvements in modeling systems and data assimilation systems have contributed to improved seasonal prediction of the Indian summer monsoon.

\section{Data and methodology}

The NMME is an MME producing both retrospective and real-time intraseasonal to interannual predictions and is comprised of global coupled atmosphere-ocean models from modeling centers in the United States and Canada (Kirtman et al. 2014). The NMME provides retrospective seasonal forecasts for 1982-2010. In this study nine models are selected from the first implementation of the NMME (phase 1; denoted here as NMME:1) and nine models from the current implementation (phase 2; denoted here as NMME: 2 as summarized in Table 1. CFSv2, CanCM3 and CanCM4 are the common models in both of the NMME phases (denoted by $\oplus$ in Table 1). The 15 models have a common re-forecast period of 28 years from 1982-2009. The number of ensemble members for each model ranges from 6 to 24, with 109 total ensemble members from nine models for NMME:1, and 110 ensemble members from nine participating models for NMME:2. Model runs are initialized every month with forecast lengths ranging from 6 to 11 months. In the present study we analyze the June-September (JJAS) seasonal means of precipitation and SST for forecasts starting 
Table 1 List of NMME models used for this study

\begin{tabular}{|c|c|c|c|c|c|c|}
\hline Model & Hindcast period & Ensemble size & $\begin{array}{l}\text { Lead time } \\
\text { (months) }\end{array}$ & Model res. (Atoms) & Model res. (ocean) & References \\
\hline \multicolumn{7}{|c|}{ Operational NMME models } \\
\hline $\mathrm{NCEP} / C F S v 2^{\oplus}$ & 1982-2010 & 24 & $0-9$ & T126L64 & MOM4L40 $0.25^{\circ} \mathrm{Eq}$ & Saha et al. (2014) \\
\hline $\begin{array}{l}\text { GFDL/CM2p1 } \\
\text { aer04 }\end{array}$ & $1982-2010$ & 10 & $0-11$ & $2 \times 2.5^{\circ} \mathrm{L} 24$ & MOM4L50 0.3 Eq & Delworth et al. (2006) \\
\hline $\begin{array}{l}\text { GFDL/CM2p5 } \\
\text { FLORB01 }\end{array}$ & $1982-2010$ & 12 & $0-11$ & C18L32 (50 Km) & $\begin{array}{l}\text { MOM5L50 } 0.3^{\circ} \mathrm{Eq} 1^{\circ} \\
\text { Polar } 1.5\end{array}$ & Vecchi et al. (2014) \\
\hline $\begin{array}{l}\text { GFDL/CM2p5 } \\
\text { FLORA06 }\end{array}$ & $1982-2010$ & 12 & $0-11$ & C18L32 (50 Km) & $\begin{array}{l}\text { MOM5L50 } 0.3^{\circ} \mathrm{Eq} 1^{\circ} \\
\text { Polar } 1.5\end{array}$ & Vecchi et al. (2014) \\
\hline $\mathrm{CanCM}^{\oplus}$ & 1982-2010 & 10 & $0-11$ & CanAM3 T63L31 & CanOM4L40 $0.94^{\circ} \mathrm{Eq}$ & Merryfieldet al. (2013) \\
\hline $\mathrm{Can} C M 4^{\oplus}$ & $1982-2010$ & 10 & $0-11$ & CanAM4 T63L35 & CanOM4L40 $0.94^{\circ} \mathrm{Eq}$ & Merryfieldet al. (2013) \\
\hline NCAR/CCSM4 & $1982-2010$ & 10 & $0-11$ & $0.9 \times 1.25^{\circ} \mathrm{L} 26$ & POPL60 $0.25^{\circ} \mathrm{Eq}$ & $\begin{array}{l}\text { Infanti and Kirtman } \\
\text { (2016) }\end{array}$ \\
\hline $\begin{array}{l}\text { NASA/GMAO } \\
062012\end{array}$ & $1982-2010$ & 11 & $0-11$ & $1 \times 1.25^{\circ} \mathrm{L} 72$ & $\mathrm{MOM} 4 \mathrm{~L} 400.25^{\circ} \mathrm{Eq}$ & Vernieres et al. (2012) \\
\hline NCAR/CESM1 & $1982-2010$ & 10 & $0-11$ & $0.9 \times 1.25^{\circ} \mathrm{L} 30$ & POPL60 $0.25^{\circ} \mathrm{Eq}$ & Tribbia (2015) \\
\hline \multicolumn{7}{|c|}{ Retired or old versions of the NMME models } \\
\hline NCEP/CFSv1 & $1982-2009$ & 15 & $0-8$ & T62L64 & MOM3L40 $0.3^{\circ} \mathrm{Eq}$ & Saha et al. (2006) \\
\hline NCAR/CCSM3 & 1982-2010 & 6 & $0-11$ & T85L26 & POPL42 $0.3^{\circ} \mathrm{Eq}$ & Kirtman and Min (2009) \\
\hline NASA/GMAO & $1982-2010$ & 11 & $0-11$ & $1 \times 1.25^{\circ} \mathrm{L} 72$ & $\mathrm{MOM} 4 \mathrm{~L} 400.25^{\circ} \mathrm{Eq}$ & Vernieres et al. (2012) \\
\hline IRI/ECHAM4f & 1982-2010 & 12 & $0-7$ & T42L19 & MOM3L25 $1.5^{\circ} \times 0.5^{\circ}$ & DeWitt (2005) \\
\hline IRI/ECHAM4a & $1982-2010$ & 12 & $0-7$ & T42L19 & MOM3L25 $1.5^{\circ} \times 0.5^{\circ}$ & DeWitt (2005) \\
\hline GFDL/CM2p1 & $1982-2010$ & 10 & $0-11$ & $2 \times 2.5^{\circ} \mathrm{L} 24$ & MOM4L50 $0.3^{\circ} \mathrm{Eq}$ & Delworth et al. (2006) \\
\hline
\end{tabular}

from May 1 initial conditions. Equal weights are given to each model in calculating the average over all models and ensemble members, denoted the multimodel ensemble mean (MMEM). The choice of reforecasts initialized in May was made in order to avoid inclusion of potential skill from the atmospheric initial conditions. It is assumed that after one month of model integration, the atmospheric initial conditions, which provide much of the skill for numerical weather forecasts at 1-15 days lead-time, have a minimal impact on the forecast skill of the ensuing seasonal mean. It is possible that forecasts initialized in May are subject to the spring predictability barrier (Torrence and Webster 1998), which may mask some of the difference in skill among models. All NMME models are re-gridded to a common $1^{\circ} \times 1^{\circ}$ resolution. The Climate Prediction Center Merged Analysis of Precipitation (CMAP) (Xie and Arkin 1997) and the optimum interpolation version 2 analysis of Reynolds et al. (2002) (OISSTv2) dataset at $1^{\circ} \times 1^{\circ}$ resolution are used as the observed precipitation and sea surface temperature, respectively. It should be noted that previous work (Cash et al. 2008) has hown that satellite based observational rainfall data products, CMAP and Global Precipitation Climatology Project (GPCP; Huffman et al. 1997) have some significant differences over the ISMR region. Rainfall maxima over Bay of Bengal has high magnitude in the CMAP as compared to GPCP. Rainfall maxima over Western Ghats is also found higher in CMAP as compared to GPCP. Therefore some of the conclusions of this study may be sensitive to the choice of CMAP as the observed rainfall product.

\subsection{Results and discussions}

The JJAS mean precipitation from CMAP and the multi model ensemble mean (MMEM) of NMME: 1 and NMME:2 are shown in Fig. $(1 \mathrm{a}-\mathrm{c})$. Local rainfall maxima over the Western Ghats, Bay of Bengal and the south equatorial ocean are well simulated in both NMME:1 and NMME:2, while rainfall over the foothills of the Himalaya is overestimated in both phases. Spatial correlations of seasonal mean rainfall over the Indo-Pacific domain are 0.92 and 0.89 for NMME: 1 and NMME:2, respectively. Seasonal mean rainfall over the region outlined in Fig. $1 \mathrm{a}\left(70^{\circ} \mathrm{E}-90^{\circ} \mathrm{E}, 10^{\circ}\right.$ $\mathrm{N}-30^{\circ} \mathrm{N}$ ) is $7.25 \mathrm{~mm} /$ day for the observations, while it is $7.93 \mathrm{~mm} /$ day and $7.73 \mathrm{~mm} /$ day for NMME: 1 and NMME:2, respectively.

In general, Fig. 1 indicates that the seasonal mean monsoon rainfall is well represented in the NMME but that there is no significant improvement in NMME: 2 as compared to NMME:1. This is further illustrated by considering the Taylor diagram (Fig. 2) of area averaged seasonal mean rainfall from the ensemble mean of the NMME models and CMAP data over Central India $\left(\mathrm{CI}\right.$ : $75^{\circ} \mathrm{E}-85^{\circ} \mathrm{E}, 16^{\circ} \mathrm{N}-26^{\circ} \mathrm{N}$; box 
Fig. 1 Spatial distribution of JJAS mean rainfall (mm/day) over the period of 1982-2009, $\mathbf{a}$ from CMAP, $\mathbf{b}$ from MMEM of NMME:1, $\mathbf{c}$ from MMEM of NMME:2, rectangle over figure a represents extend monsoon region $\left(70^{\circ} \mathrm{E}-90^{\circ} \mathrm{E}, 10^{\circ} \mathrm{N}-30^{\circ}\right.$ $\mathrm{N})$,rectangle over figure $\mathbf{b}$ represents Central India region $\left(75^{\circ}\right.$ $\left.\mathrm{E}-85^{\circ} \mathrm{E}, 16^{\circ} \mathrm{N}-26^{\circ} \mathrm{N}\right)$. All the forecasts are initialized in May and verified for JJAS mean

Fig. 2 Taylor diagram area averaged seasonal mean rainfall, a over central India $\left(75^{\circ} \mathrm{E}-85^{\circ} \mathrm{E}\right.$, $16^{\circ} \mathrm{N}-26^{\circ} \mathrm{N}$, Ocean data points are excluded), $\mathbf{b}$ over the region selected in figure 1a: $\left(70^{\circ} \mathrm{E}-90^{\circ} \mathrm{E}, 10^{\circ} \mathrm{N}-30^{\circ} \mathrm{N}\right)$ for individual NMME models and NMME: 1 and NMME:2 as compared to Observations (CMAP) over the period of 1982-2009. All the forecasts are initialized in May and verified for JJAS mean
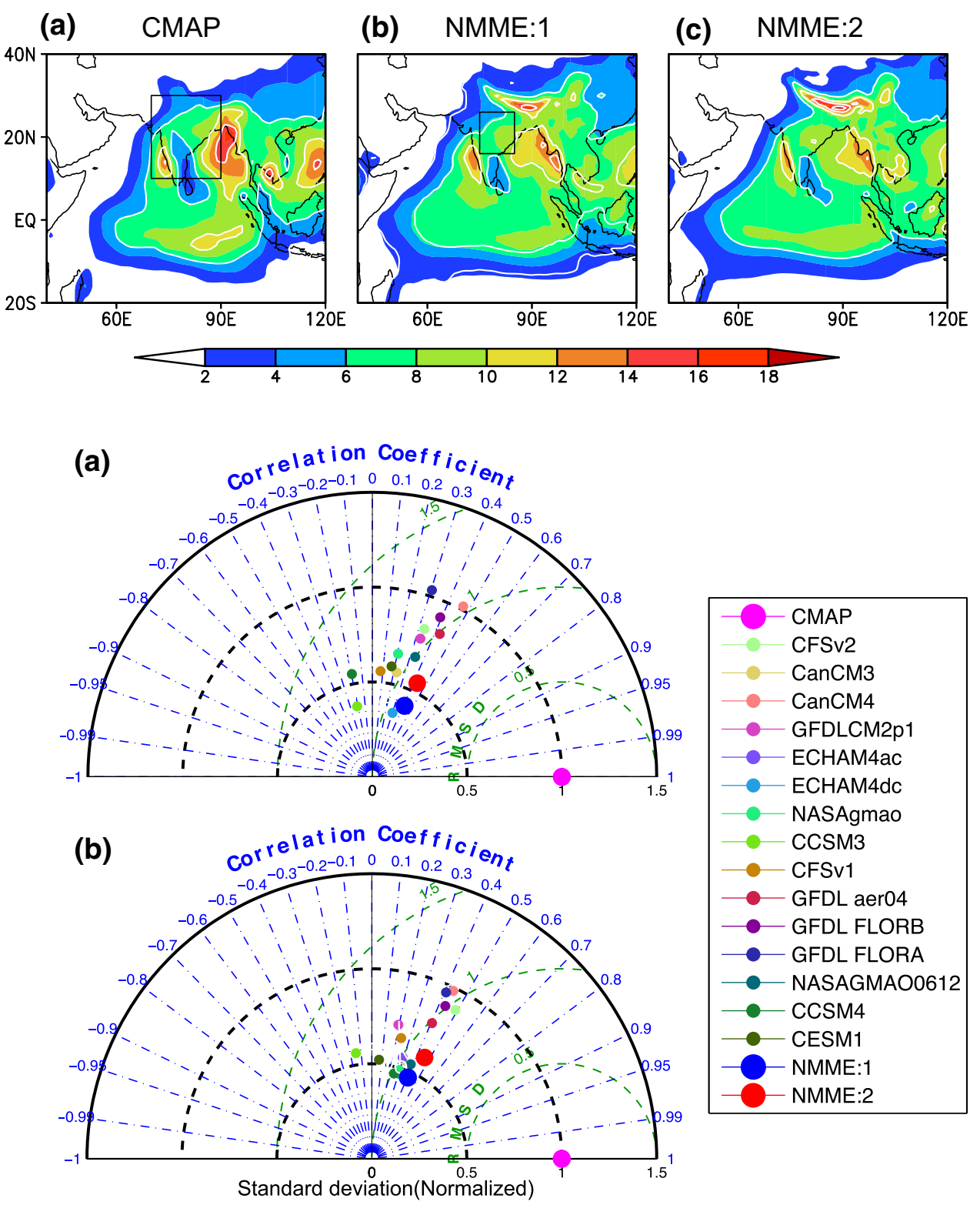

NMME:2

shown over Fig. 1b) and over a larger region $\left(70^{\circ} \mathrm{E}-90^{\circ} \mathrm{E}\right.$, $10^{\circ} \mathrm{N}-30^{\circ} \mathrm{N}$; box shown over Fig. 1a) that includes the western Ghats and part of the Bay of Bengal. Most of the NMME models are closely clustered on Taylor diagram around 0.2-0.5, with the exception of CCSM3 and CCSM4 which are negatively correlated with observations. It is again hard to distinguish between the NMME: 1 and NMME:2 models in this metric, emphasizing that there is no significant improvement seasonal forecast skill in NMME: 2 relative to NMME:1. The ensemble mean of each NMME model consistently has less year-to-year variability as compared to observations for the selected regions. The MMEMs for each phase do show some differences in skill, predicting seasonal mean rainfall over India with moderate correlations of 0.4 and 0.5 in NMME: 1 and NMME:2, respectively. The reduced interannual variability shown by the model ensemble means (Fig. 2a, b) is due to the averaging of individual members, which increases the signal-to-noise ratio. We have examined the interannual variability of the individual model realizations (results not shown) and found that the interannual variability of the individual model realizations is comparable to the observations. Interannual variability of the MMEM of NMME: 2 is larger than that of NMME: 1 , but the difference is statistically insignificant at the $95 \%$ confidence level.

The differences between simulated and observed climatological seasonal mean rainfall for the NMME: 1 and NMME: 2 models are shown in Figs. 3 and 4, respectively. There are several intramodel differences and similarities among the NMME seasonal rainfall simulations. Almost 
Fig. 3 Difference (ModelObs.) between ensemble mean JJAS climatological rainfall of NMME: 1 and Observations (CMAP) from 1982-2009, all the forecasts are initialized in May and verified for JJAS mean

Fig. 4 Difference (ModelObs.) between ensemble mean JJAS climatological rainfall of NMME: 2 and Observations (CMAP) from 1982-2009, all the forecasts are initialized in May and verified for JJAS mean
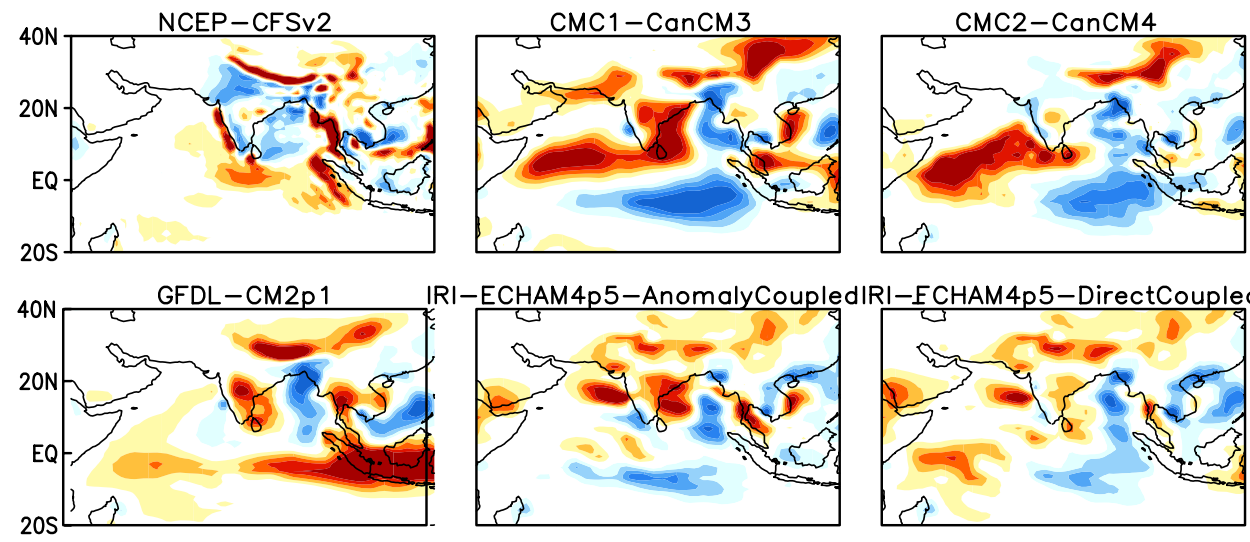

RI-ECHAM4p5-AnomalyCoupledIRI-FCHAM4p5-DirectCoupled
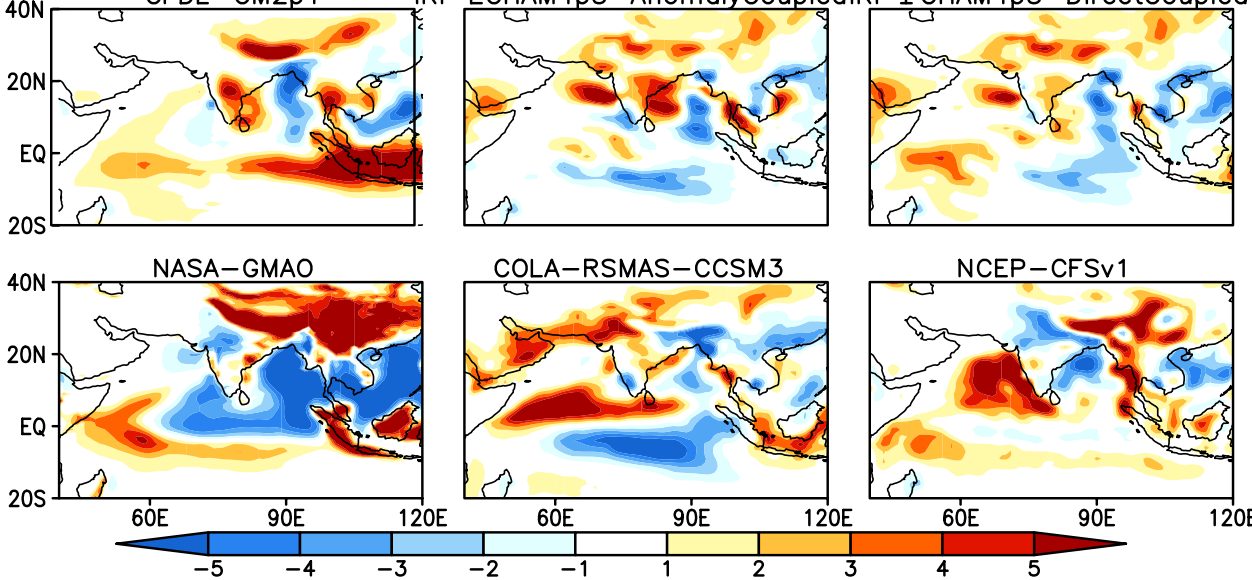

COLA-RSMAS-CCSM3
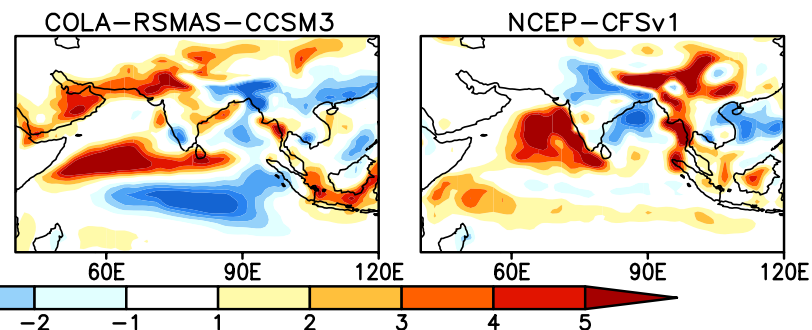

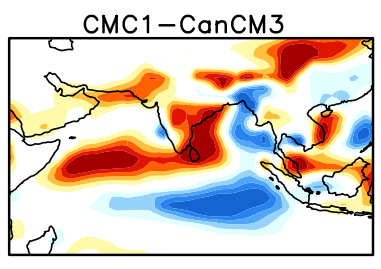

GFDL-CM2p5-FLOR-B01
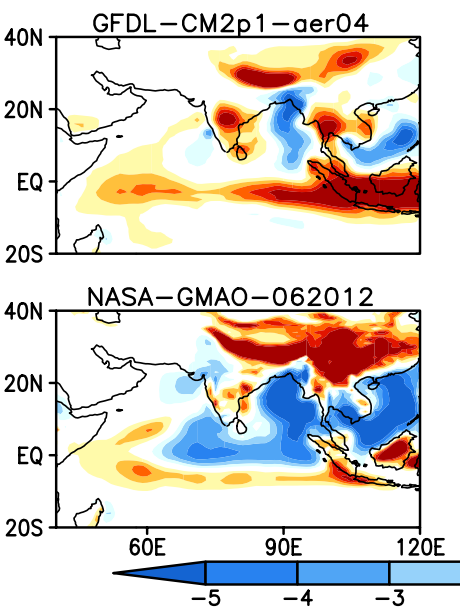

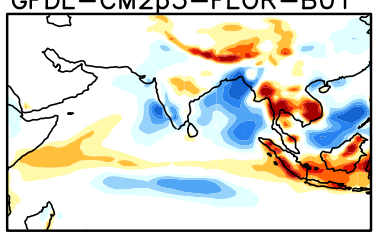

COLA-RSMAS-CCSM4

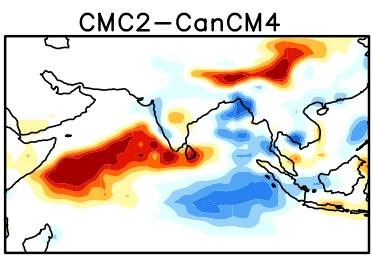

GFDL-CM2p5-FLOR-A06

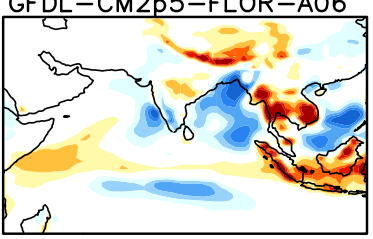

NCAR.CESM 1

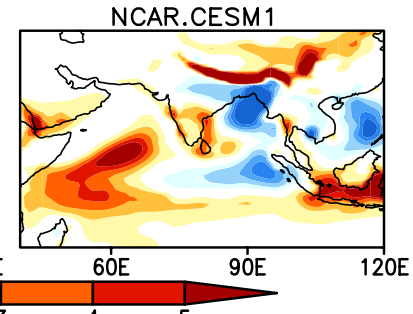

all of the models overestimate rainfall over the foothills of the Himalayas, the western and equatorial Indian Ocean, and underestimate rainfall over the Bay of Bengal. Over the Indian land region ECHAM4p5-AC, ECHAM4p5-DC, CCSM3, Can-CM3 and CCSM4 overestimate rainfall, while both versions of CFS and NASA-GMAO underestimate rainfall. Can-CM4 and GFDL-CM2p5-FLOR simulate seasonal mean rainfall reasonably well.
When we consider the MMEMs for NMME:1 and NMME:2 (Fig. 5) the large intramodel difference are mostly canceled out and the root mean square error (RMSE) over the study region (see Fig. 1) is 2.76 and $2.29 \mathrm{~mm} /$ day for NMME: 1 and NMME:2, respectively. Rainfall over the foothills of Himalaya is overestimated in both MMEMs by more than $5 \mathrm{~mm} /$ day. Both MMEMs also overestimate the seasonal mean rainfall over the western Indian Ocean and 
Fig. 5 Difference between multimodel ensemble mean JJAS climatological rainfall from observations (NMME Obs.), $\mathbf{a}$ for NMME: 1 and $\mathbf{b}$ for NMME:2, over the period of 1982-2009

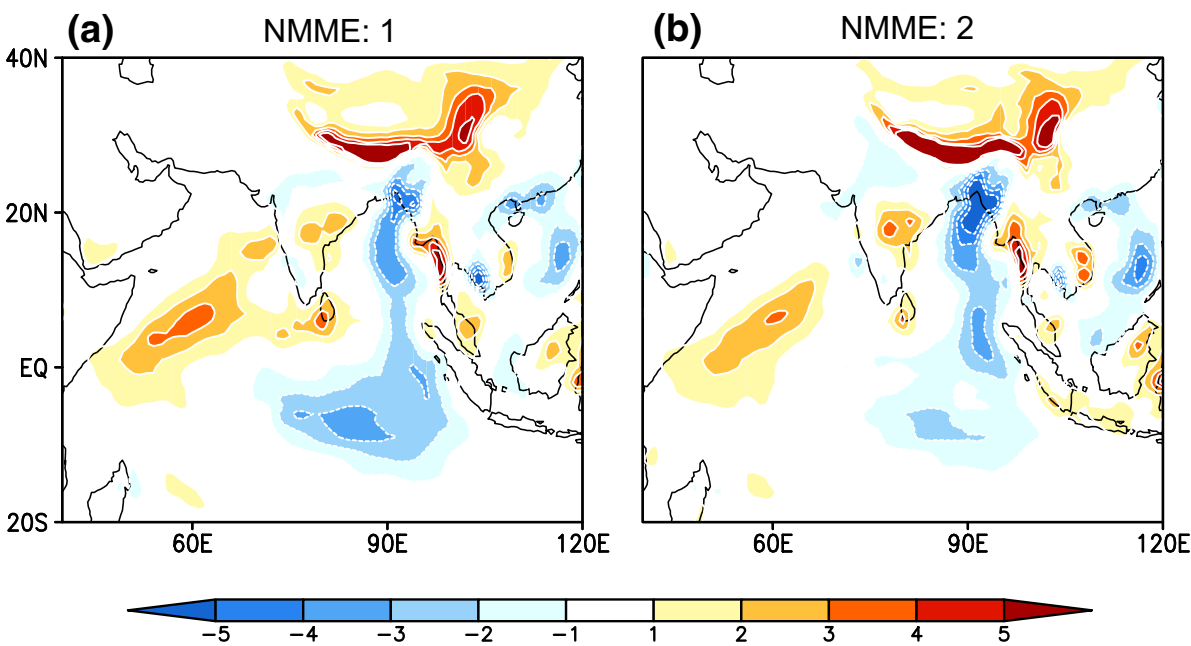

underestimate it over the Bay of Bengal, although the wet bias over western Indian ocean and dry bias over Bay of Bengal are reduced in NMME:2. Over the land mass region of India rainfall is well simulated in both of phases of NMME. The ensemble means of the seasonal mean ISMR was also analyzed separately for the two phases, after excluding common models (CFSv2, CMC1 and CMC2) and the conclusions are remain same (figures not shown). Taken together we find there is no significant improvement in seasonal mean rainfall over the Indo-Pacific domain from NMME: 1 and NMME:2, despite the inclusion of improved versions of the participating models in NMME:2. We have analyzed the ensemble mean of seasonal mean rainfall from older version models (NASA-GMAO, NCAR-CCSM3 and GFDLCM2p1) and improved version of similar models (NASA-GMAO, NCAR-CCSM4 and GFDLCM2p5-FLOR) and found that improvement in each modeling system is small as compared to their individual mean bias (figures are not shown). Therefore the improvements in modeling systems are not being reflected in the simulations of the seasonal mean ISMR.

In addition to representing climatological mean rainfall, simulation of interannual variability is another key and challenging aspect of ISMR seasonal prediction. ISMR seasonal mean rainfall shows considerable year-to-year variability, which is known to be strongly influenced by slowly varying boundary conditions (Charney and Shukla 1981). The skill of the NMME in representing the interannual variability of ISMR is shown in Fig. 6. Standardized seasonal rainfall anomalies for CMAP (red), MMEM of NMME: 1 (green) and NMME:2 (Blue) are represented as histograms for each year for the CI (Fig. 1b) and extended region (Fig. 1a) for the period 1982-2009. Similar to the seasonal means, there is no significant improvement in this metric in NMME: 2 relative to NMME: 1 . Over the CI region NMME: 2 has a correlation of 0.42 with observations, while NMME: 1 is 0.39 . The difference is similar for the extended region $\left(70^{\circ} \mathrm{E}-90^{\circ} \mathrm{E}, 10^{\circ}\right.$
$\mathrm{N}-30^{\circ} \mathrm{N}$ ), where correlations are 0.46 for NMME: 2 and 0.40 for NMME: 1 . To evaluate the forecast skill of seasonal mean rainfall, we have compared standardized anomalies relative to the model climatology. Thus the systematic errors are removed and standardized anomalies below or above one standard deviation are considered as drought or flood years, respectively. The MMEM of NMME: 2 is able to simulate drought during 1987, 1992, 2002 and floods during 2005, while giving false alarms for droughts in 1997 and for flood in 19851999 and 2007 over the CI region. The NMME:2 is able to forecast normal monsoon years more skillfully as compared to extreme monsoon rainfall. Heidke skill score (Heidke 1926) for the forecast verification is calculated for the MMEM of NMME:1 and NMME:2 for the period of 1982-2009 over the CI region and the extended region $\left(70^{\circ} \mathrm{E}-90^{\circ} \mathrm{E}, 10^{\circ} \mathrm{N}-30^{\circ} \mathrm{N}\right)$. Standardize seasonal rainfall anomalies of CMAP, MMEM of NMME: 1 and NMME:2 are divided into three categories, (above normal exceeding upper tercile), below normal (lower tercile) and normal (between both tercile) on the basis of the observed rainfall anomalies. Heidke skill scores (HSS) for both of the regions are shown in Table 2. While there is no standard cut off value for HSS for a forecast to be considered ?good?, values above 0.2 are considered as good scores. As we can see that in Table 2, HSS over central Indian region is poor for the normal and above normal seasonal mean monsoon rainfall in NMME: 1 and NMME:2, while below normal monsoon seasonal mean rainfall is predicted with high HSS for both of NMME phases. Over the extended region $\left(70^{\circ} \mathrm{E}-90^{\circ} \mathrm{E}\right.$, $10^{\circ} \mathrm{N}-30^{\circ} \mathrm{N}$ ), HSS is moderately positive except for below normal rainfall in NMME: 2 and the forecasts are skillful as compared to chance forecast in both phases of NMME. For the central India region only NMME: 2 forecasts are skillful as compared to chance

Turning our attention to the spatial distribution of model skill, we show the pointwise anomaly correlation coefficient 
Fig. 6 Histograms of standardized seasonal mean monsoon rainfall anomaly averaged over a over CI: $\left(75^{\circ} \mathrm{E}-85^{\circ} \mathrm{E}, 16^{\circ}\right.$ $\mathrm{N}-26^{\circ} \mathrm{N}$, Ocean data points are excluded), $\mathbf{b}$ over the region selected in figure 1a: $\left(70^{\circ} \mathrm{E}-\right.$ $\left.90^{\circ} \mathrm{E}, 10^{\circ} \mathrm{N}-30^{\circ} \mathrm{N}\right)$, form Observations (red bars), multimodel ensemble mean NMME: 1 (green bars) and multimodel ensemble mean NMME:2 (blue bars) for the period 1982-2009, dashed black line denotes \pm 1 standard deviation of seasonal anomalies, abbreviation $\mathrm{CC}$ is stands for correlation coefficient
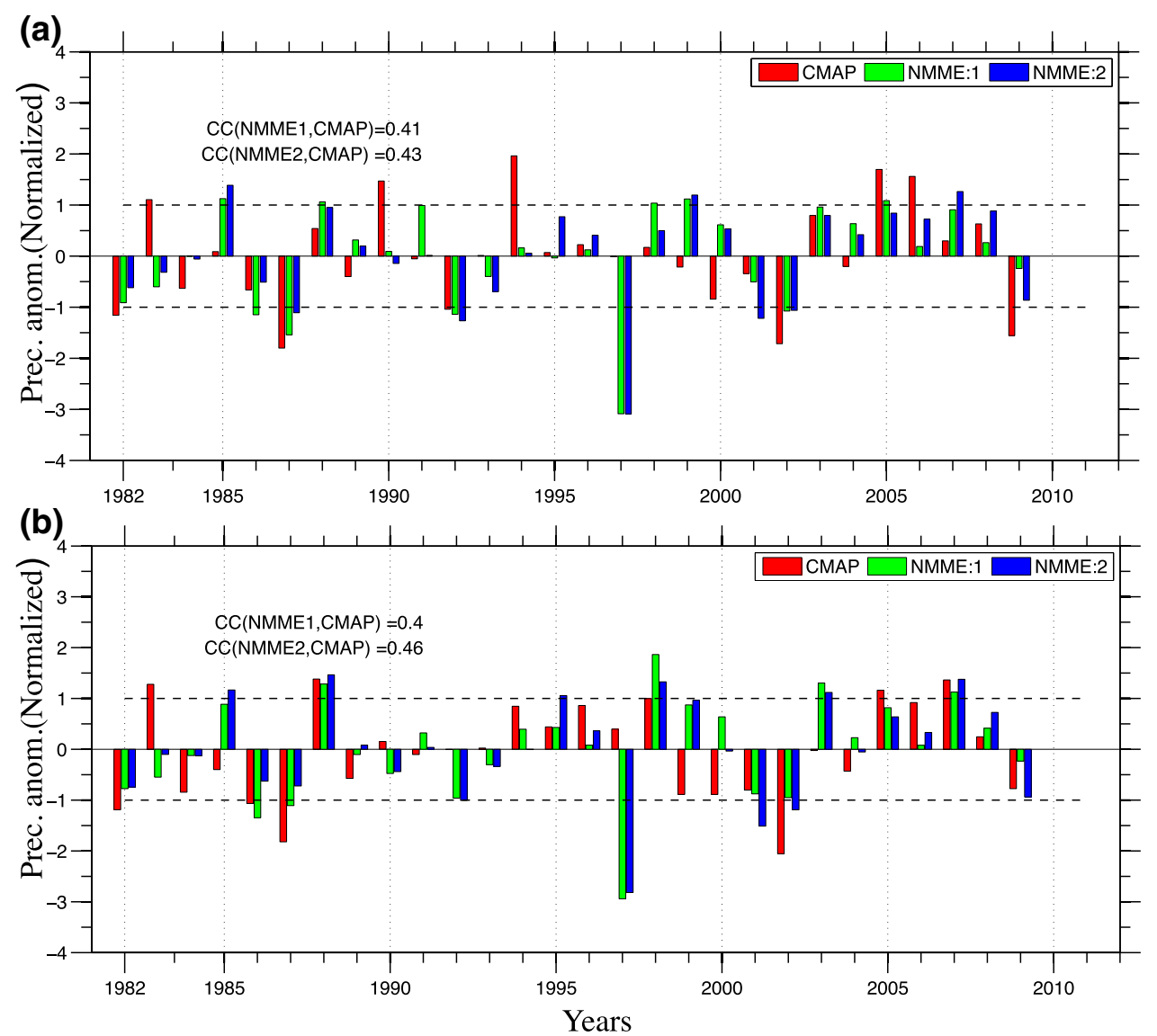

Table 2 Heidke skill score for forecast verification

\begin{tabular}{cccl}
\hline Phase & Above normal & Normal & Below normal \\
\hline CI: $\left(75^{\circ} \mathrm{E}-85^{\circ} \mathrm{E}, 16^{\circ} \mathrm{N}-26^{\circ} \mathrm{N}\right)$ & & \\
NMME: 1 & -0.02 & -0.03 & 0.40 \\
NMME: 2 & 0.18 & -0.19 & 0.50 \\
Extended region: & $\left(70^{\circ} \mathrm{E}-90^{\circ} \mathrm{E}, 10^{\circ} \mathrm{N}-30^{\circ} \mathrm{N}\right)$ & \\
NMME: 1 & 0.30 & 0.47 & 0.19 \\
NMME: 2 & 0.24 & 0.25 & 0.0 \\
\hline
\end{tabular}

between the MMEMs of NMME: 1 and NMME:2 and observations for seasonal mean rainfall (Fig. 7a, b, respectively) for the period of 1982-2009. Both phases of the NMME have higher skill over the ocean relative to land. The NMME ensembles have no skill over the northwestern part of India but show moderate skill over the central and northeastern regions. We find that skill for the NMME ensembles is improved over the Bay of Bengal, the Arabian sea, and the equatorial Indian ocean in NMME:2.

As noted in the Introduction, the interannual and intraseasonal variability of ISMR is strongly influenced by SST variability over the Pacific and Indian Oceans. Positive anomalies over the eastern Pacific (El Niño events) tend to produce below normal rainfall over India, while negative anomalies (La Niña events) lead to above normal rainfall (e.g. Sikka 1980; Pant and Parthasarathy 1981; Rasmusson and Carpenter 1983; Gadgil et al. 2003, 2004). SST over the Indian Ocean has also been shown to have a strong link with ISMR (Saji et al. 1999; Ashok et al. 2001; Krishnamurthy and Kirtman 2009). Thus, simulation of SST and the teleconnections with ISMR are important for accurate representation of the seasonal mean ISMR and its interannual variability. Differences between the ensemble mean SST bias for JJAS over the period of 1982-2009 for NMME:1 and NMME:2 are shown in Figs. 8 and 9, respectively. The NMME models are cold biased by $1-2^{\circ} \mathrm{K}$ over the equatorial Pacific Ocean, with the exception of the GFDL-CM2p5FLOR which has a warm bias over the same region. Northern Pacific warm biases and northern Atlantic Ocean cold biases are a common feature of all NMME models. SST over the Indian Ocean is more inconsistent, with cold biases in some models and warm biases in others. For example, CFSv2 has a large cold bias over Indian Ocean while CanCM3, Can-CM4, GFDL-aer04 and NCAR-CESM1 show warm biases. Figure 10 shows the grand ensemble mean of JJAS mean SST between $60^{\circ} \mathrm{S}-60^{\circ} \mathrm{N}$. The equatorial Pacific Ocean cold bias is present in both sets of hindcasts, but is improved in NMME: 2 relative to NMME:1. The west Pacific is biased warm in both sets of hindcasts, but the warm bias is 
Fig. 7 Pointwise seasonal mean rainfall anomaly correlation, a between multimodel ensemble mean NMME: 1 and CMAP b between multimodel ensemble mean NMME: 2 and CMAP, over the period of 1982-2009. Forecast are initialized in May and verified for JJAS mean. The contour indicates regions where correlations are statistically significant at $95 \%$
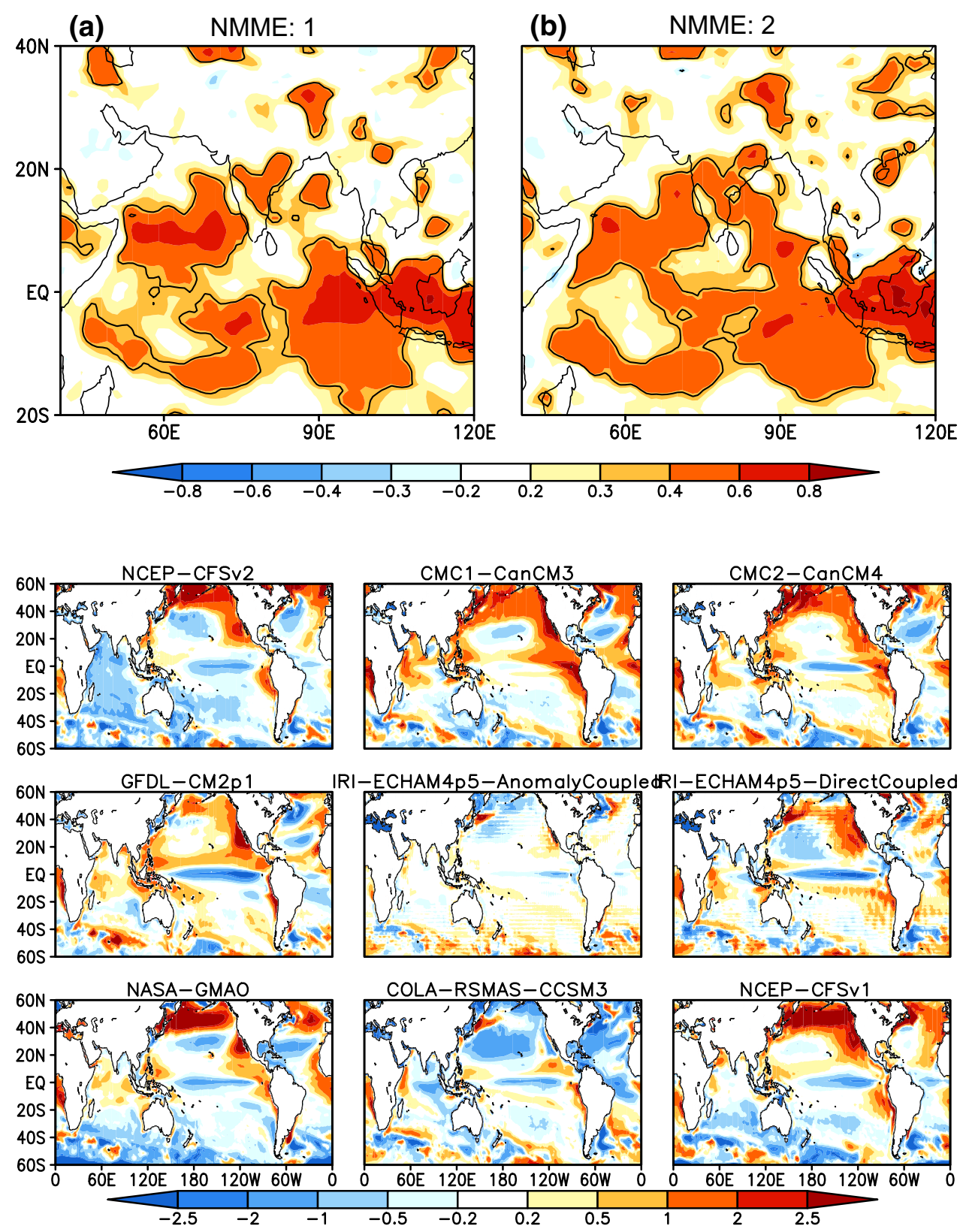

increased in NMME:2. The Indian Ocean MMEMs have less bias than the individual model hindcasts, due to error cancellation. The Pacific and Atlantic Ocean are both biased cold between $20^{\circ} \mathrm{N}-40^{\circ} \mathrm{N}$ by $1-2^{\circ} \mathrm{K}$, and we again find the bias increases from NMME: 1 to NMME:2. Overall, the seasonal mean SST biases are slightly larger in NMME:2 compared to NMME: 1

The biases in the equatorial Pacific Ocean are particularly significant for the simulation of the monsoon, as this region is known to act as the dominant forcing in the observed interannual variability of ISMR (Kumar et al. 2006). Accurate simulation of SST anomalies over this region is thus critical to skillful dynamical seasonal prediction of the Indian monsoon (Shukla and Paolino 1983; Kumar et al. 1999;
Gadgil et al. 2007). Figure 11 shows a comparison of the JJAS Niño 3.4 index (standardized area average SST average over the region $170^{\circ} \mathrm{E}-120^{\circ} \mathrm{W}, 5^{\circ} \mathrm{S}-5^{\circ} \mathrm{N}$ ) from OISSTv2 for NMME: 1 and NMME:2 for the period of 1982-2009. We can see that the MMEMs are able to capture all major El Niño events except for 2002 and all La Niña events except for 2003 and 2007. Overall the grand means for NMME: 1 and NMME: 2 are able predict the seasonal mean SST anomalies with high correlation scores of 0.85 and 0.86 , respectively.

In Fig. 12 we show the pointwise anomaly correlation for JJAS mean SST between the grand ensemble mean from the NMME hindcasts and observed SST over the period of $1982-2009$ between $60^{\circ} \mathrm{S}-60^{\circ} \mathrm{N}$. Correlations with observed 
Fig. 9 Difference between ensemble mean JJAS climatological SST of NMME: 2 models and Observations (OISSTv2) (Model-Obs.), over the period of 1982-2009, forecasts are initialized in May and verified for JJAS mean
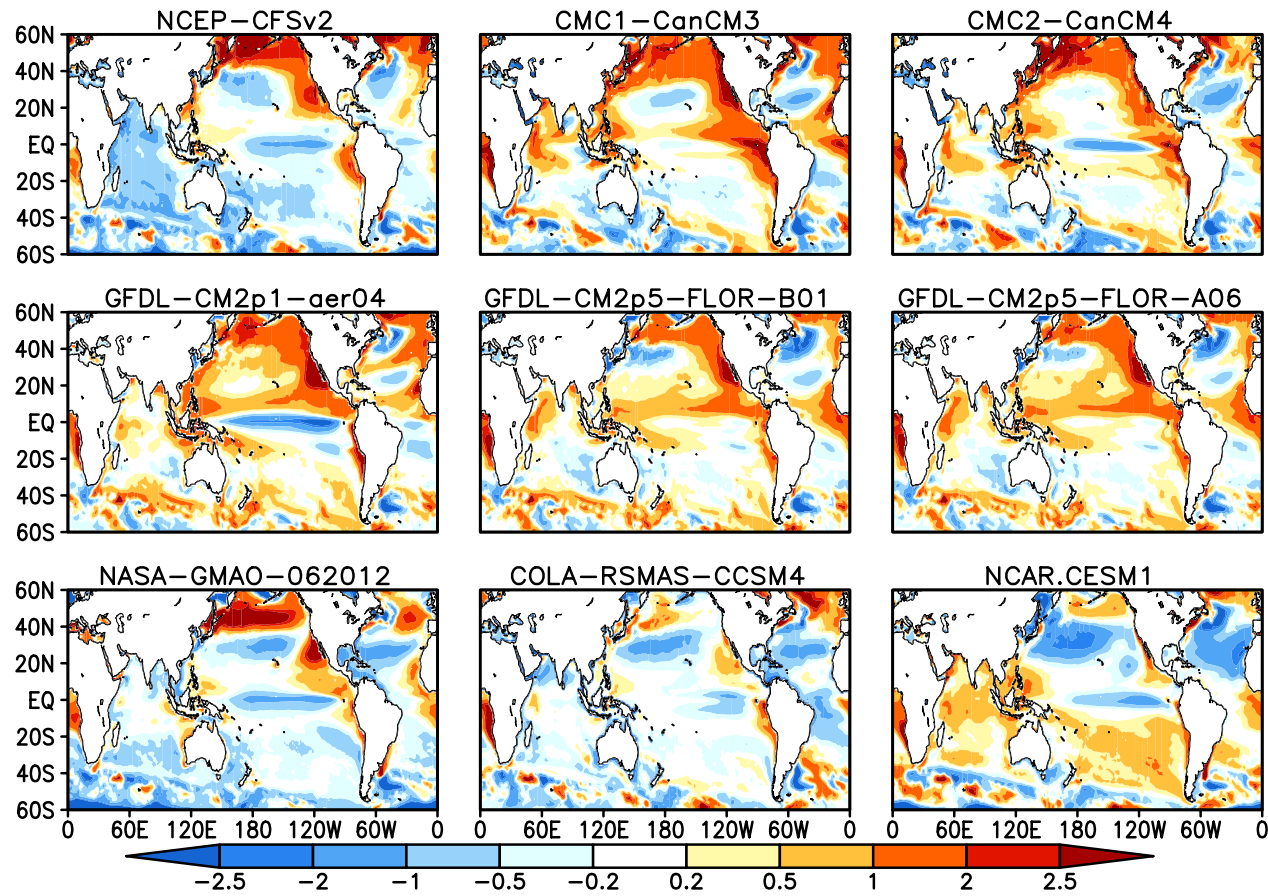

(a)

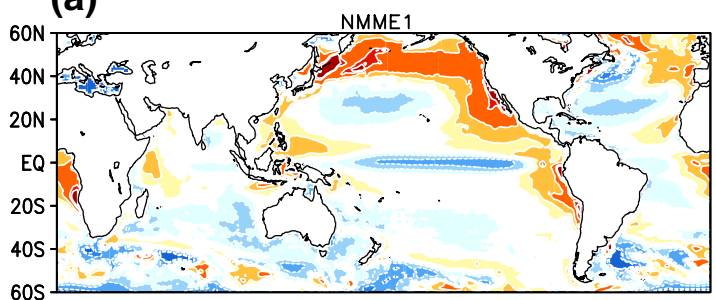

(b)

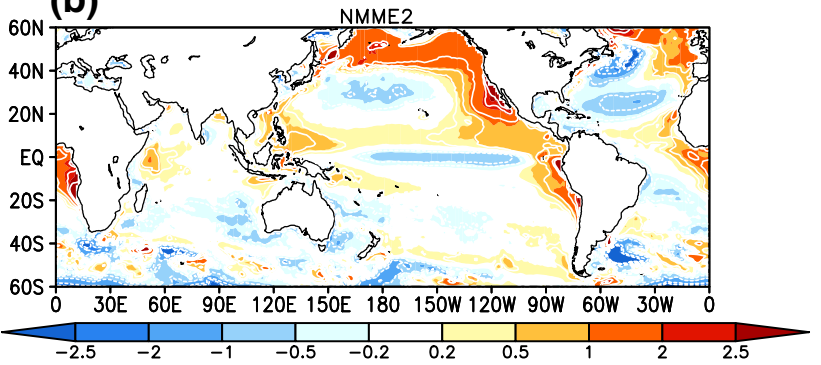

Fig. 10 Difference between multimodel ensemble mean JJAS climatological SST from observations (OISSTv2) (Model-Obs.), a for NMME:1 and b for NMME:2, over the period of 1982-2009, forecasts are initialized in May and verified for JJAS mean

SST are high for both of the NMME hindcasts in the central and eastern tropical Pacific Ocean, with magnitudes increasingly slightly in NMME:2. Overall skill remains greater than 0.6 everywhere except for the warm pool region in the western Pacific Ocean. SST forecast skill is improved over the Indian, Atlantic and Pacific Ocean basins in NMME: 2 as compared to NMME:1.
Some earlier studies (e.g., Palmer et al. 1992; Wang et al. 2008) suggest that long lead predictability of Indian monsoon comes from predictability of the El Niño-Southern Oscillation (ENSO). Under this theory, skillful prediction of seasonal mean rainfall and its interannual variability depends upon how skillfully models simulate ENSO variability and how well ENSO-monsoon teleconnections are represented in simulations. This motivates us to examine the simultaneous correlation between seasonal mean ISMR index over the CI region, JJAS mean SST from observations, and the grand mean of NMME: 1 and NMME:2 (Fig. 13). We can see that ISMR is strongly influenced by SST in NMME hindcast as compared to observations. Rainfall over $\mathrm{CI}$ is negatively correlated with eastern-equatorial Pacific Ocean SST in the observations, but in the grand means of the NMME hindcasts, the rainfall-SST coupling is much stronger. We also find that SST over north Atlantic Ocean is positively correlated with the rainfall over India, similar to the simultaneous positive correlation between ISMR and subtropical Atlantic SST anomalies found by Rajeevan and Sridhar (2008). This relationship is well simulated in the grand mean of the NMME hindcasts, but it is overestimated as compared to observations. SST anomalies over the warm pool region are positively correlated with ISMR, and the association is well captured by the NMME hindcasts. In contrast, the positive simultaneous correlations between north Pacific SST anomalies and ISMR are too strong. The overestimation of the magnitude of the ENSO-monsoon teleconnection is similar to that of the DEMETER and ENSEMBLE experiments (Preethi et al. 2010; Rajeevan et al. 2012). However, in making the comparison between observations 
Fig. 11 JJAS mean Nino 3.4 (area averaged SSTA $\left(170^{\circ}\right.$ $\mathrm{E}-120^{\circ} \mathrm{W}, 5^{\circ} \mathrm{S}-5^{\circ} \mathrm{N}$ ) index over the period of 1982-2009 from OISSTv2 (black solid), from MMEM of NMME: 1 (dashed blue) and from MMEM of NMME:2 (dashed red), forecasts are initialized in May and verified for JJAS mean

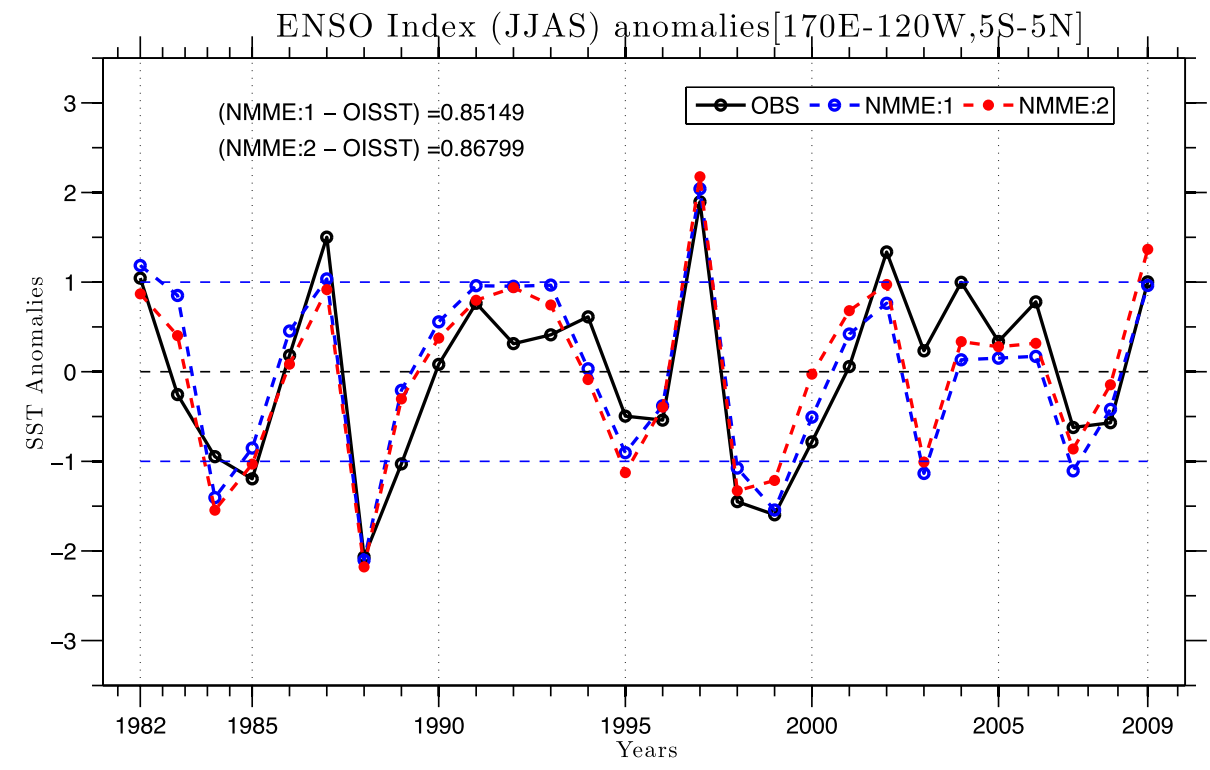

(a)

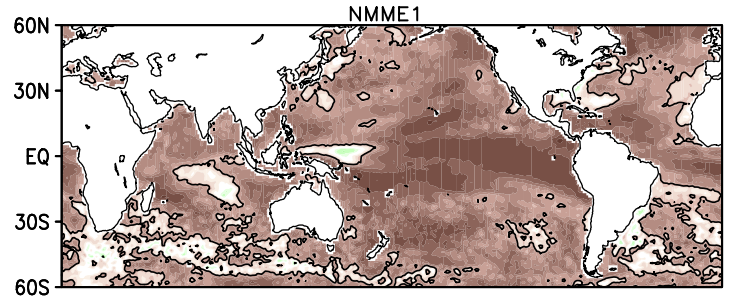

(b)

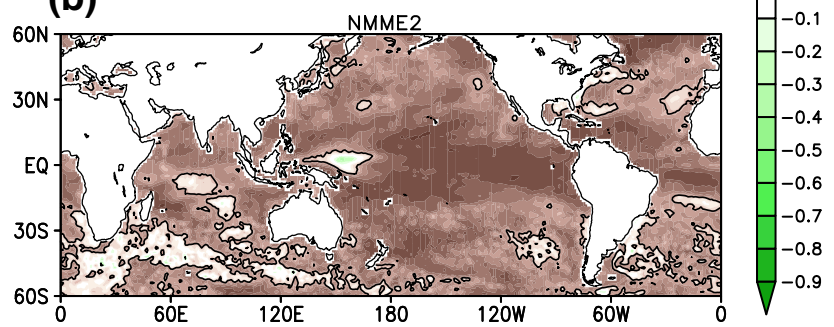

Fig. 12 Pointwise JJAS mean SST anomaly correlation, a between multimodel ensemble mean NMME:1 and OISSTv2 (b) between multimodel ensemble mean NMME:2 and OISSTv2, over the period of 1982-2009. Forecasts are initialized in May and verified for JJAS mean. The contour indicates regions where correlations are statistically significant at $95 \%$

and ensemble mean one should recall that ensemble averaging suppresses the influence of climate noise (see Cash et al. 2017), which can lead to increased correlation strength relative to observations. It is important to note that SST in the Indian Ocean is also linked to interannual variability of ISMR (Saji et al. 1999; Webster et al. 1999), and that Fig. 13 indicates teleconnections between ISMR and SST in Indian Ocean are not well simulated in the NMME hindcasts. In the observations SST anomalies over the Western Equatorial Indian Ocean (WEIO: $50^{\circ} \mathrm{E}-70^{\circ} \mathrm{E}, 10^{\circ} \mathrm{S}-10^{\circ} \mathrm{N}$ ) are (a)

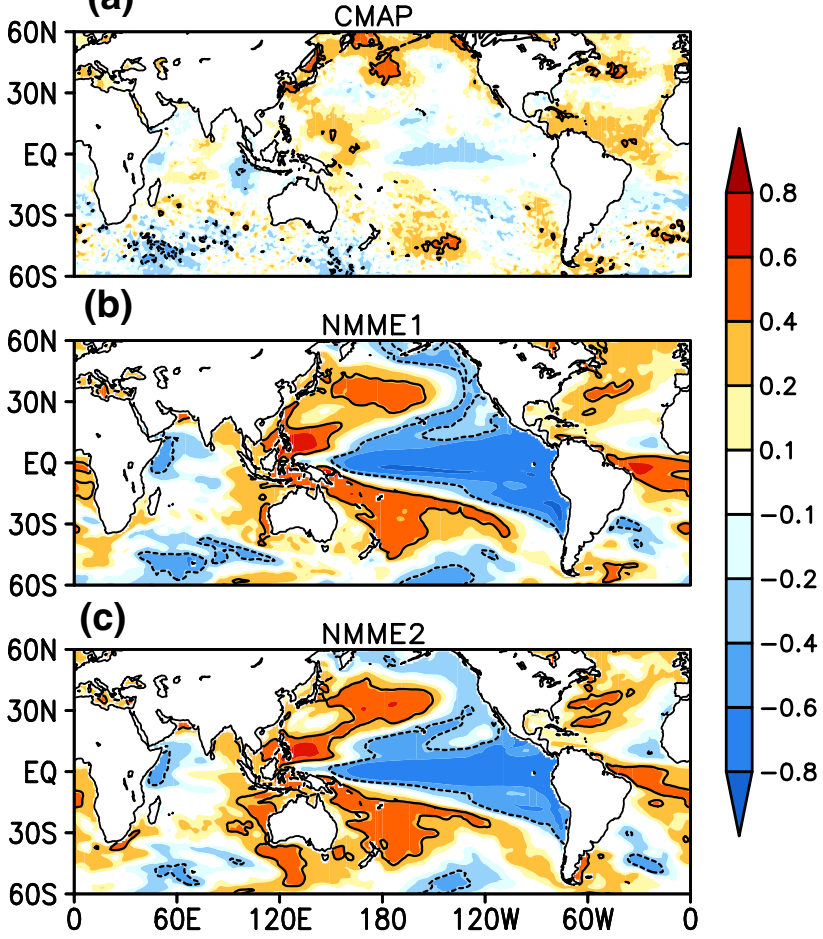

Fig. 13 Correlation coefficient between central india $\left(75^{\circ} \mathrm{E}-85^{\circ} \mathrm{E}, 16^{\circ}\right.$ $\mathrm{N}-26^{\circ} \mathrm{N}$ ) averaged JJAS mean rainfall and JJAS mean SST between $60^{\circ} \mathrm{S}-60^{\circ} \mathrm{N}$ over the period $1982-2009$ for a CMAP and OISSTv2, b for MMEM of NMME:1, c for MMEM of NMME:2, forecasts are initialized in May and verified for JJAS mean. The contour indicates regions where correlations are statistically significant at $95 \%$

positively correlated with ISMR, while they are negatively correlated in the NMME hindcasts. Likewise Eastern Equatorial Indian Ocean (EEIO: $90^{\circ} \mathrm{E}-110^{\circ} \mathrm{W}, 0^{\circ}-10^{\circ} \mathrm{S}$ ) SST anomalies are positively correlated with ISMR in NMME 
hindcasts, while in the observations they are negatively correlated. The NMME hindcasst thus do not capture the teleconnection between ISMR and Indian Ocean SST anomalies. This problem is by no means unique to the NMME; a study by Nanjundiah et al. (2013) analyzed retrospective forecast from 7 coupled ocean atmosphere models and found that only ECMWRF correctly simulated the Equatorial Indian Ocean Oscillation (EQUINO)-ISMR link. This may be one reason why the NMME falsely predicted droughts during the normal monsoon years of 1997 and a normal monsoon year during the flood year of 1983 (note that there is no major difference in teleconnection pattern between NMME: 1 and NMME:2). SST anomalies in the Indian Ocean during 1997 and 1983 are thought to have played an important role in overcoming the negative impact of ENSO during the same years (e.g. Gadgil et al. 2007). It is interesting to note that SST in the Indian Ocean is less biased in comparison to the Pacific and Atlantic Oceans but the Indian Ocean telconnection with ISMR is represented more poorly in the NMME hindcasts. Another interesting point to be noted from Fig. 7b of Nanjundiah et al. (2013) is that even though ECMWF can capture Indian Ocean teleconnections correctly this model still gives false alarm of droughts during the normal monsoon years of 1983 and 1997.

Finally, we turn our attention to the remote association between the tropical Pacific and Indo-Pacific precipitation. As shown in Fig. 12, SST anomalies in the eastern Pacific Ocean are predicted skillfully, providing potential predictability for regional rainfall. Pointwise simultaneous correlations between the Niño 3.4 index and seasonal mean rainfall over Indo-Pacific domain are shown in Fig. 14 . Rainfall over the Indian landmass, the equatorial Indian Ocean and the maritime continent are all strongly anti-correlated with Niño 3.4 in the NMME hindcasts. NMME hindcast is thus able to simulate the correct sign of the association, but overestimates the magnitude ENSO-ISMR relationship relative to the observations. The strong ENSO-ISMR relationship suggests an overly strong oceanic influence on the atmosphere in the NMME, although as noted above the magnitude of the correlations may be exaggerated by use of the ensemble mean. However a cursory examination(results not shown here) indicates that even in time series formed by selecting individual ensemble members, the ENSO-ISMR correlation is higher than the observed.

\section{Conclusions}

In this study we have analyzed the seasonal mean and interannual variability of the Indian summer monsoon rainfall (ISMR) in nine global ocean-atmosphere coupled models participating in the NMME: 1 and nine global ocean-atmosphere coupled models participating in the NMME: 2 from 1982-2009. Models are evaluated over the Indo-Pacific domain starting from May initial conditions. The two phases of the NMME are compared to each other, in part to determine what progress, if any, has been made through the inclusion of new models and improved versions of existing models in the NMME. We find the MMEM of the NMME represents seasonal mean rainfall with a modest level of skill. Both phases of the NMME simulate excessive rainfall over the western Indian Ocean and the foothills of the Himalayas, while producing deficient rainfall over the Bay of Bengal and the eastern Indian Ocean. The deficient rainfall over the Bay of Bengal and excessive rainfall over Himalayan foothills are the most common bias among the all NMME models, while biases over the Indian land region can be of either sign. Biases in the MMEMs in both phases of the NMME are strongly reflective of those of the individual models. Improvements in modeling systems and data assimilation systems is not reflected in simulations of seasonal

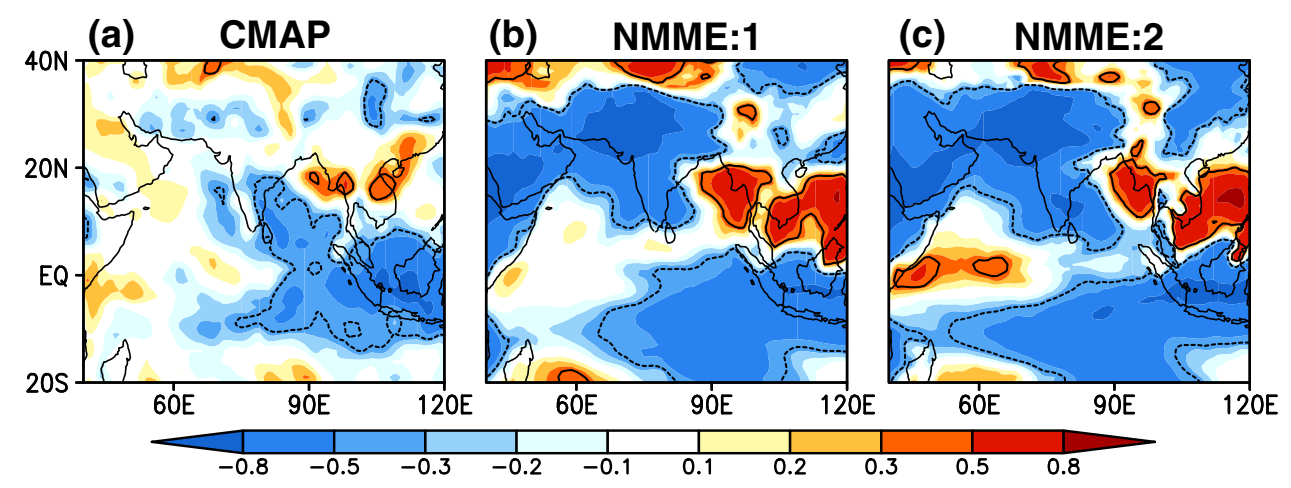

Fig. 14 Simultaneous correlation coefficient between JJAS mean Nino 3.4 (area averaged SSTA $\left(170^{\circ} \mathrm{E}-120^{\circ} \mathrm{W}, 5^{\circ} \mathrm{S}-5^{\circ} \mathrm{N}\right)$ index and JJAS mean rainfall anomaly over Indo-Pacific domain from 19822009 for a OISSTv2 and CMAP, b for MMEM of NMME:1, $\mathbf{c}$ for
MMEM of NMME:2, forecasts are initialized in May and verified for JJAS mean. The contour indicates regions where correlations are statistically significant at $95 \%$ 
mean of ISMR because improvements in each modeling system are small as compared to their individual mean bias.

These common systematic biases across the models likely limit the performance of the MMEM method for the seasonal prediction of ISMR. Previous studies (e.g. Zhou et al. 2009) have also shown that the performance of MMEMs is relatively low for the Indian and Asian monsoon regions. This is may be due uncertainties in the representation of subgrid scale process and coupling between large scale circulation and convection in MMEMs in general and reflected in the NMME.

The majority of rainfall over the Indian sector falls during June-September, with year to year variability of ISMR at roughly $10 \%$ of the seasonal mean. Accurate prediction of this relatively low amplitude interannual variability is a challenging and important aspect of seasonal prediction. To examine the skill of intrannual variations we have used the correlation coefficient between predicted and observed seasonal mean rainfall as a metric. As noted in the Introduction, an objective of this study is to compare the seasonal mean monsoon rainfall skill of NMME phase 1 and NMME phase 2. Earlier work (Kirtman et al. 2014) indicated that improvement in data assimilation and modeling systems contributed to improved forecast quality in NMME phase 2. However, we find the skill of seasonal prediction of Indian summer monsoon rainfall is nearly the same in NMME:2 (0.46) as compared to NMME: 1 (0.40); the NMME is still not able to accurately predict extremes (drought/floods) of rainfall. Therefore seasonal monsoon rainfall forecast is not improved by the improvement in data assimilation system and modeling system in the NMME phase 2 . The inability to predict extremes can also be seen in both the DEMETER and ENSEMBLE experiments (Preethi et al. 2010; Rajeevan et al. 2012). Both DEMETER and ENSEMBLE, as well as NMME predicted droughts during the normal monsoon years of 1997 and normal monsoon year during flood year of 1983. This suggests that similar biases found in the DEMETER and ENSEMBLE models exist in the models used in the NMME.

The interannual and intraseasonal time scale variability of ISMR is strongly influenced by SST variability in the Pacific and Indian Oceans. Pointwise correlation of seasonal mean SST from NMME and observations revealed that the skill of interannual predictions is high (0.6-0.9) for most ocean basins, and improved in NMME:2 relative to NMME: 1 . The most common seasonal mean SST biases in NMME models are cold equatorial Pacific and subtropical Atlantic Ocean and warm biases in northern Pacific Ocean. These biases also remain in the MMEMs, and while the cold bias over the equatorial Pacific is improved in NMME:2, the re-forecasts of the Indian Ocean warm bias worsen. We find that the NMME simulates the observed interannual variability of the NINO3.4 index with correlations greater than 0.8 . We also find that predictions of the ENSO anomalies are remain same in both NMME: 1 NMME:2.

In this work we also examine teleconnection patterns that affect the monsoon, and find that teleconnections in the MMEMs are stronger than in the observations. The MMEMs capture the ENSO-monsoon, Atlantic-monsoon and west Pacific-monsoon teleconnections correctly, but fail to correctly represent the association with the Indian Ocean. The EQUINO-ISMR relationship in particular is opposite to what is observed. The teleconnection between the ISMR and Indian Ocean SST also was not represented well in the DEMETER and ENSEMBLES models. This again suggests a common systematic error in coupled model forecasts. This error in association may be the reason why the NMME predicted droughts during the normal monsoon years of 1997 and a normal monsoon year during the flood year of 1983, as SST anomalies in the Indian Ocean during 1997 and 1983 played an important role in overcoming the negative impact of El Niño events (Gadgil et al. 2007). The NMME captures the negative correlation between ENSO and the monsoon, but the influence of ENSO on ISMR is stronger in the NMME than is observed. The overly strong ENSO-ISMR relationship suggests that oceanic influence on atmosphere may be too strong in NMME, particularly when comparing the MMEM to observations.

Overall the NNME shows modest skill in predicting Indian summer monsoon rainfall and its interannual variability. However, the NMME models show common biases in rainfall over Indian Ocean, are unable to predict the extremes in seasonal rainfall, and show only modest increases in skill from NMME: 1 to NMME:2. The failure to represent the monsoon-EQUINO teleconnection in particular may be a critical limitation of the models comprising the NMME, and the association between this link and the prediction of extremes of seasonal rainfall clearly warrants further investigation.

Acknowledgements Funding of COLA for this study is provided by Grants from NSF (AGS-1338427), NOAA (NA09OAR4310058 and NA14OAR4310160), NASA (NNX14AM19G), and the ONR Grant (N00014-15-1-2745). We acknowledge NOAA MAPP, NSF, NASA, and the DOE that support the NMME-Phase II system, and we thank the climate modeling groups (Environment Canada, NASA, NCAR, NOAA/GFDL, NOAA/NCEP, and University of Miami) for producing and making available their model output. NOAA/NCEP, NOAA/ CTB, and NOAA/CPO jointly provided coordinating support and led development of the NMME-Phase II system. We thank the anonymous reviewers for their constructive comments which helped improve this paper.

Open Access This article is distributed under the terms of the Creative Commons Attribution 4.0 International License (http://creativeco mmons.org/licenses/by/4.0/), which permits unrestricted use, distribution, and reproduction in any medium, provided you give appropriate credit to the original author(s) and the source, provide a link to the Creative Commons license, and indicate if changes were made. 


\section{References}

Ashok K, Guan Z, Yamagata T (2001) Impact of the Indian Ocean dipole on the relationship between the Indian monsoon rainfall and enso. Geophys Res Lett 28:4499-4502

Bollasina MA, Ming Y, Ramaswamy V (2011) Anthropogenic aerosols and the weakening of the south asian summer monsoon. Science 334:502-505

Boos WR, Kuang Z (2010) Dominant control of the south Asian monsoon by orographic insulation versus plateau heating. Nature 463:218-222

Buizza R, Houtekamer P, Toth Z, Pellerin G, Wei M, Zhu Y (2005) A comparison of the ecmwf, msc and ncep global ensemble prediction systems. Mon Weather Rev 133:1076-1097

Cash BA, Rodó X, Kinter JL III, Fennessy MJ, Doty B (2008) Differing estimates of observed bangladesh summer rainfall. J Hydrometeorol 9:1106-1114

Cash BA, Barimalala R, Kinter JL, Altshuler EL, Fennessy MJ, Manganello JV, Molteni F, Towers P, Vitart F (2017) Sampling variability and the changing ENSO-monsoon relationship. Clim Dyn 48(11-12):4071-4079

Chakraborty A, Nanjundiah RS, Srinivasan J (2002) Role of Asian and African orography in Indian summer monsoon. Geophys Res Lett 29(20). https://doi.org/10.1029/2002GL015522

Charney JG, Shukla J, Lighthill J, Pearce RP (eds) (1981) Predictability of monsoons monsoon dynamics. Cambridge University Press, Cambridge, pp 99-109

DeWitt DG (2005) Retrospective forecasts of interannual sea surface temperature anomalies from, (1982) to present using a directly coupled atmosphere-ocean general circulation model. Mon Weather Rev 133:2972-2995

Delworth TL, Broccoli AJ, Rosati A, Stouffer RJ, Balaji V, Beesley JA, Cooke WF, Dixon KW, Dunne J, Dunne KA, Durachta JW, Findell KL, Ginoux P, Gnanadesikan A, Gordon CT, Griffies SM, Gudgel R, Harrison MJ, Held IM, Hemler RS, Horowitz LW, Klein SA, Knutson TR, Kushner PJ, Langenhorst AR, Lee H-C, Lin S-J, Lu J, Malyshev SL, Milly PCD, Ramaswamy V, Russell J, Schwarzkopf MD, Shevliakova E, Sirutis JJ, Spelman MJ, Stern WF, Winton M, Wittenberg AT, Wyman B, Zeng F, Zhang R (2006) Gfdl's cm2 global coupled climate models. part i: Formulation and simulation characteristics. J Clim 19:643-674

Gadgil S, Rajeevan M, Francis P (2007) Monsoon variability: links to major oscillations over the equatorial pacific and Indian oceans. Curr Sci 93:182-194

Gadgil S, Sajani S (1998) Monsoon precipitation in the amip runs. Clim Dyn 14:659-689

Gadgil S, Vinayachandran P, Francis P (2003) Droughts of the Indian summer monsoon: role of clouds over the Indian Ocean. Curr Sci 85:1713-1719

Gadgil S, Abrol YP, Rao SP (1999) On growth and fluctuation of Indian foodgrain production. Curr Sci 76:548-556

Gadgil S, Vinayachandran PN, Francis PA, Gadgil S (2004) Extremes of the Indian summer monsoon rainfall, ENSO and equatorial Indian ocean oscillation. Geophys Res Lett 31(12):L12213. https ://doi.org/10.1029/2004GL019733

Gadgil S, Rajeevan M, Nanjundiah R (2005) Monsoon predictionwhy yet another failure? Curr Sci 88:1389-1400

Hagedom R, Doblas-Reyes FJ, Palmer TN (2004) The rationale behind the success of multi-model ensembles in seasonal forecasting-I. Basic concept. Tellus A 57:219-233

Hahn D, Manabe S (1975) The role of mountains in the south asian monsoon circulation. J Atmos Sci 33:2461-2463

Heidke P (1926) Berechnung des erfolges und der güte der windstärkevorhersagen im sturmwarnungsdienst. Geografiska Ann:301-349
Hewitt CD, Griggs DJ (2004) Ensembles-based predictions of climate changes and their impacts (ensembles). Eos 85:566

Huffman GJ, Adler RF, Arkin P, Chang A, Ferraro R, Gruber A, Janowiak J, McNab A, Rudolf B, Schneider U (1997) The global precipitation climatology project (gpcp) combined precipitation dataset. Bull Am Meteorol Soc 78:5-20

Infanti JM, Kirtman BP (2016) Prediction and predictability of land and atmosphere initialized CCSM4 climate forecasts over North America. J Geophys Res Atmos 121:12690-12701. https://doi. org/10.1002/2016JD024932

Joshi PC, Desai PS (1985) The satellite-determined thermal structure of heat low during Indian south-west monsoon season. Adv Space Res 5:57-60

Kang IS, Jin K, Wang B, Lau K-M, Krishnamurthy JSV, Schubert S, Wailser D, Stern W, Kitoh A, Meehl G, Kanamitsu M, Galin V, Satyan V, Park CK, Liu Y (2002) Intercomparison of the climatological variations of asian summer monsoon precipitation simulated by $10 \mathrm{gcms}$. Clim Dyn 19:383-395

Kirtman BP, Min D (2009) Multimodel ensemble enso prediction with ccsm and cfs. Mon Weather Rev 137:2908-2930

Kirtman BP, Min D, Infanti JM, Kinter JL III, Paolino DA, Zhang Q, Van Den Dool H, Saha S, Mendez MP, Becker E et al (2014) The north american multimodel ensemble: phase-1 seasonal-tointerannual prediction; phase-2 toward developing intraseasonal prediction. Bull Am Meteorol Soc 95:585-601

Krishnamurthy V, Kirtman BP (2009) Relation between Indian monsoon variability and sst. J Clim 22:4437-4458

Kumar KK, Rajagopalan B, Cane MA (1999) On the weakening relationship between the Indian monsoon and enso. Science 284:2156-2159

Kumar KK, Rajagopalan B, Hoerling M, Bates G, Cane M (2006) Unraveling the mystery of Indian monsoon failure during el niño. Science 314:115-119

Lau K-M, Kim K-M (2006) Observational relationships between aerosol and Asian monsoon rainfall, and circulation. Geophys Res Lett 33(21):L21810. https://doi.org/10.1029/2006GL027546

Merryfield WJ, Lee W-S, Boer GJ, Kharin VV, Scinocca JF, Flato GM, Ajayamohan R, Fyfe JC, Tang Y, Polavarapu S (2013) The canadian seasonal to interannual prediction system. part i: Models and initialization. Mon Weather Rev 141:2910-2945

Nanjundiah RS, Francis P, Ved M, Gadgil S (2013) Predicting the extremes of Indian summer monsoon rainfall with coupled oceanatmosphere models. Curr Sci 104:1380-1393

Palmer T, Brankovic Č, Viterbo P, Miller M (1992) Modeling interannual variations of summer monsoons. J Clim 5:399-417

Palmer T, Doblas-Reyes F, Hagedorn R, Alessandri A, Gualdi S, Andersen U, Feddersen H, Cantelaube P, Terres J, Davey M et al (2004) Development of a european multimodel ensemble system for seasonal-to-interannual prediction (demeter). Bull Am Meteorol Soc 85:853-872

Palmer T, Shutts GJ, Hagedorn R, Doblas-Reyes FJ, Jung T, Leutbecher M (2005) Representing model uncertainty in weather and climate predictions. Annu Rev Earth Planet Sci 33:163-193

Palmer TN, Alessandri A, Andersen U, Cantelaube P, Davey M, Delécluse P, Déqué M, Diez E, Doblas-Reyes FJ, Feddersen H, Graham R (2004) Development of a european multi-model ensemble system for seasonal to inter-annual prediction. Bull Am Meteorol Soc 85:853-872

Pant G, Parthasarathy SB (1981) Some aspects of an association between the southern oscillation and Indian summer monsoon. Arch Meteorol Geophys Bioclimatol Ser B 29:245-252

Preethi B, Kripalani R, Kumar KK (2010) Indian summer monsoon rainfall variability in global coupled ocean-atmospheric models. Clim Dyn 35:1521-1539 
Prell WL, Kutzbach JE (1992) Sensitivity of the Indian monsoon to forcing parameters and implications for its evolution. Nature 360:647-652

Rajeevan M, Unnikrishnan C, Preethi B (2012) Evaluation of the ensembles multi-model seasonal forecasts of Indian summer monsoon variability. Clim Dyn 38:2257-2274

Rajeevan M, Nanjundiah RS (2009) Coupled model simulations of twentieth century climate of the Indian summer monsoon. Platin Jubilee Spec Vol Ind Academy Sci 537-568

Rajeevan M, Sridhar L (2008) Inter-annual relationship between Atlantic Sea surface temperature anomalies and Indian summer monsoon. Geophys Res Lett 35(21):L21704. https://doi. org/10.1029/2008GL036025

Ramage CS (1996) The summer atmospheric circulation over the Arabian Sea. J Atmos Sci 23:144-150

Rasmusson EM, Carpenter TH (1983) The relationship between eastern equatorial pacific sea surface temperatures and rainfall over india and sri lanka. Mon Weather Rev 111:517-528

Reynolds RW, Rayner NA, Smith TM, Stokes DC, Wang W (2002) An improved in situ and satellite sst analysis for climate. J Clim 15:1609-1625

Saha S, Moorthi S, Wu X, Wang J, Nadiga S, Tripp P, Behringer D, Hou Y-T, Chuang H-Y, Iredell M et al (2014) The ncep climate forecast system version 2. J Clim 27:2185-2208

Saha S, Nadiga S, Thiaw C, Wang J, Wang W, Zhang Q, Van den Dool H, Pan H-L, Moorthi S, Behringer D et al (2006) The ncep climate forecast system. J Clim 19:3483-3517

Saha SK, Pokhrel S, Salunke K, Dhakate A, Chaudhari HS, Rahaman H, Sujith K, Hazra A, Sikka DR (2016) Potential predictability of Indian summer monsoon rainfall in NCEP CFSv2. J Adv Model Earth Syst 8:96-120. https://doi.org/10.1002/2015MS000542

Saji N, Goswami B, Vinayachandran P, Yamagata T (1999) A dipole mode in the tropical Indian ocean. Nature 401:360-363

Schwierz C, Appenzeller C, Davies HC, Liniger MA, Muller W, Stocker TF, Yoshimore M (2006) Challenges posed by and approaches to the study of seasonal-to-decadal climate variability. Clim Change 79:31-63

Sharmila S, Pillai P, Joseph S, Roxy M, Krishna R, Chattopadhyay R, Abhilash S, Sahai A, Goswami B (2013) Role of oceanatmosphere interaction on northward propagation of Indian summer monsoon intra-seasonal oscillations (MISO). Clim Dyn 41:1651-1669

Shukla J, Moolay DA (1987) Empirical prediction of the summer monsoon rainfall over India. Mon Weather Rev 115:695-703

Shukla J, Paolino DA (1983) The southern oscillation and long-range forecasting of the summer monsoon rainfall over India. Mon Weather Rev 111:1830-1837

Sikka D (1980) Some aspects of the large scale fluctuations of summer monsoon rainfall over India in relation to fluctuations in the planetary and regional scale circulation parameters. Proc Indian Acad Sci Earth Planet Sci 89:179-195
Sikka DR (1997) Desert climate and its dynamics. Curr Sci 72:35-46 Sperber KR, Annamalai H, Kang I-S, Kitoh A, Moise A, Turner A, Wang B, Zhou T (2013) The asian summer monsoon: an intercomparison of cmip5 vs. cmip3 simulations of the late 20th century. Clim Dyn 41:2711-2744

Torrence C, Webster PJ (1998) The annual cycle of persistence in the el nño/southern oscillation. Q J R Meteorol Soc 124:1985-2004

Tribbia J (2015) Ncar contribution to a us national multi-model ensemble (nmme) isi prediction system, Technical report. University Corporation for Atmospheric Research, Boulder

Vecchi GA, Delworth T, Gudgel R, Kapnick S, Rosati A, Wittenberg AT, Zeng F, Anderson W, Balaji V, Dixon K, Jia L, Kim H-S, Krishnamurthy L, Msadek R, Stern WF, Underwood SD, Villarini G, Yang X, Zhang S (2014) On the seasonal forecasting of regional tropical cyclone activity. J Clim 27:7994-8016

Vernieres G, Keppenne C, Rienecker MM, Jacob J, Kovach R (2012) The GEOS-ODAS, description and evaluation. NASA Tech Rep Series Glob Mod Data Ass NASA/TM 30:104606

Walker GT (1925) Correlation in seasonal variations of weather? A further study of world weather. Mon Weather Rev 53:252-254

Wang B, Lee J-Y, Kang I-S, Shukla J, Kug J-S, Kumar A, Schemm J, Luo J-J, Yamagata T, Park C-K (2008) How accurately do coupled climate models predict the leading modes of asian-australian monsoon interannual variability? Clim Dyn 30:605-619

Wang B, Wu R, Li T (2003) Atmosphere-warm ocean interaction and its impacts on Asian-Australian monsoon variation. J Clim 16:1195-1211

Wang B, Kang I, Lee J (2004) Ensemble simulations of Asian-Australian monsoon variability by 11 AGCMS. J Clim 17:803-818

Webster PJ, Magana VO, Palmer T, Shukla J, Tomas R, Yanai M, Yasunari T (1998) Monsoons: processes, predictability, and the prospects for prediction. J Geophys Res Oceans 103:14451-14510

Webster PJ, Moore AM, Loschnigg JP, Leben RR (1999) Coupled ocean-atmosphere dynamics in the Indian ocean during 1997-98. Nature 401:356-360

Wu G, Zhang Y (1998) Tibetan plateau forcing and timing of the monsoon onset over South Asia and South China sea. Mon Weather Rev 126:913-927

Xie P, Arkin PA (1997) Global precipitation: A 17-year monthly analysis based on gauge observations, satellite estimates, and numerical model outputs. Bull Am Meteorol Soc 78:2539

Yanai M, Li C, Song Z (1992) Seasonal heating of the Tibetan plateau and its effects on the evolution of the Asian summer monsoon. J Meteorol Soc Jpn 70:319-351

Zhou T, Wu B, Scaife A, Brönnimann S, Cherchi A, Fereday D, Fischer A, Folland C, Jin K, Kinter J et al (2009) The clivar c20c project: which components of the asian-australian monsoon circulation variations are forced and reproducible? Clim Dyn 33:1051-1068 